\title{
Using Geographic Information Systems to Present Nongeographical Data: An Example Using 2-Way Thermogradient Plate Data
}

\author{
Catherine S. Tarasoff, ${ }^{1}$ Mounir Louhaichi, ${ }^{2}$ \\ Carol Mallory-Smith, ${ }^{3}$ and Daniel A. Ball ${ }^{3}$ \\ Authors are ${ }^{1}$ Graduate Research Assistant, Crop and Soil Science, Oregon State University, Corvallis, OR 97330; \\ ${ }^{2}$ Research Associate, Rangeland Resources, Oregon State University, Corvallis, OR 97330; and \\ ${ }^{3}$ Professors, Crop and Soil Science, Oregon State University, Corvallis, OR 97330.
}

\begin{abstract}
"A picture is worth a thousand words" is a familiar truism that is aptly suited to the dilemma of presenting complex research results involving multiple explanatory variables. An example of such a scenario is the use of 2-way thermogradient plates to study optimal germination temperatures and germination over time to answer a variety of biological questions. Two-way thermogradient plates produce a plethora of seed germination data, the value of which quickly becomes obscured in cumbersome tabular data formats. Problems related to comprehensible data presentation can swell when germination over time is incorporated into an experiment. Although somewhat unorthodox, Geographic Information Systems-based techniques are powerful tools that provide a clear and visually evident presentation of seed germination data to the reader.
\end{abstract}

\section{Resumen}

"Una foto dice más que mil palabras," es una frase popular la cual es apropiada para el dilema de presentar los complejos resultados de investigación que involucran múltiples variables explicatorias. Un ejemplo de tal escenario es el uso de los platos con termogradiente en dos sentidos para estudiar las temperaturas óptimas de germinación a través del tiempo para dar respuesta a una variedad de preguntas biológicas. Los platos de termogradiente en dos sentidos producen una abundancia de datos de germinación de las semillas, sin embargo, el valor de ellos rápidamente viene a ser se obscurecido en abrumadores formatos tabulares. Los problemas relacionados en la presentación comprensible de los datos pueden aumentar cuando en un experimento se incorpora la germinación a través del tiempo. Aunque algo no ortodoxo, las técnicas basadas en Sistemas de Información Geográfica (GIS) proveen una poderosa herramienta la cual da al lector una presentación clara y evidentemente visual de los datos de los germinación de las semillas.

Key Words: GIS, thermogradient plate, kriging, germination

\section{INTRODUCTION}

Studying the variation of a dependent variable as a function of 2 continuous explanatory variables is a scientific procedure practiced throughout a range of disciplines. Currently, there are a variety of methods, such as tables and 3-dimensional graphs, that illustrate the effect of the continuous explanatory variables on the dependent variable. For example, one might study the effect of light and sugar concentrations on the density of bacteria colonization over a period of time. The discussion and techniques presented here are for 1 example: seed germination over time on a 2-way thermogradient plate. However, the reader is invited to explore other opportunities within their research to modify and expand on these techniques.

Thermogradient plates are used by seed biologists in various disciplines to study optimal germination temperatures and germination over time to answer a variety of biological questions (Larsen et al. 1973; Webb et al. 1987; Lodge and

Correspondence: Catherine S. Tarasoff, Crop and Soil Science, Oregon State University, Corvallis, OR 97330. Email: catherine.tarasoff@oregonstate.edu

Manuscript received 9 August 2004; manuscript accepted 9 October 2004.
Whalley 2002; Young et al. 2003). Thermogradient plates in general provide not discrete temperature intervals but rather a gradient of temperatures, usually a result from cold and hot water passing through pipes under the table surface (Larsen 1971). The 2-way thermogradient (Fig. 1) plate allows researchers to monitor germination responses to alternating temperatures over a time continuum. However, the amount of data produced from a 2-way thermogradient plate presents a challenge to the researcher when trying to present the data in an easily comprehensible visual format for publication and/or presentation.

It is generally understood that a researcher has 90 seconds to entice an audience with a poster at professional meetings and less than 2 minutes to convey the complete package of their research (O'Connor 1991; University of Guelph 2003). Given the obvious time limitation for reviewers at professional meetings, it is in the researcher's best interest to present data in a visually striking and easily interpreted format.

Typically, researchers present their data in tabular form (Larsen et al. 1973; Webb et al. 1987; Lodge and Whalley 2002; Young et al. 2003) such as displayed in Table 1. The tabular format allows for the presentation of precise data results, 


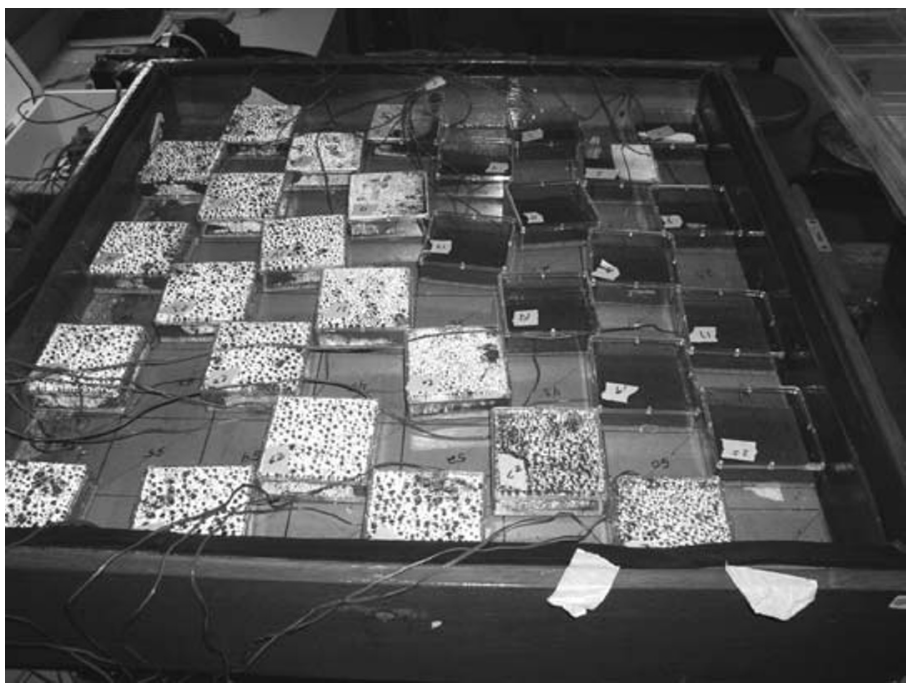

Figure 1. Example of a 2-way thermogradient plate with germination boxes and temperature monitoring thermocouples. Approximate size of plate is $1 \mathrm{~m}^{2}$.

including descriptive statistical conclusions, but does not present a visually clear interpretation of the data, especially germination over time intervals or interpolation beyond the actual data points collected. However, there exists an opportunity to use Geographic Information Systems (GIS)-based techniques to present thermogradient plate data in a visually clear format that utilizes mathematical formulae to interpolate germination beyond the data points collected. This technical note details the steps necessary to create an improved and efficient presentation of 2-way thermogradient plate data using GIS.

\section{METHOD}

\section{GIS Application}

The primary application of GIS is the presentation and manipulation of spatially related geographical data. In GIS, the XY coordinates represent the intersection of easting and northing meridians on the Earth's surface. A $\mathrm{z}$ value can be

Table 1. Tabular format of the mean germination data presented in Figure 2. Numbers in parentheses represent $\pm 95 \%$ confidence intervals for germination values (alpha $=0.05$ ).

\begin{tabular}{|c|c|c|c|c|c|c|c|c|c|}
\hline \multicolumn{10}{|c|}{ Percent Germination } \\
\hline & \multicolumn{9}{|c|}{ Daytime Temperature $\left({ }^{\circ} \mathrm{C}\right)$} \\
\hline & & 5 & 10 & 15 & 20 & 25 & 30 & 35 & 40 \\
\hline \multirow{8}{*}{ 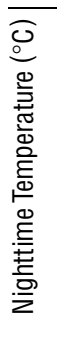 } & 5 & $0(0)$ & & $2(2)$ & & $53(7)$ & & $48(7)$ & \\
\hline & 10 & & $0(0)$ & & $45(7)$ & & $86(5)$ & & $0.5(1)$ \\
\hline & 15 & $0(0)$ & & $38(7)$ & & $84(5)$ & & $70(6)$ & \\
\hline & 20 & & $32(7)$ & & $68(7)$ & & $88(5)$ & & $0(0)$ \\
\hline & 25 & $26(6)$ & & $80(6)$ & & $65(7)$ & & $61(7)$ & \\
\hline & 30 & & $78(6)$ & & $83(5)$ & & $53(7)$ & & $0.5(1)$ \\
\hline & 35 & $13(5)$ & & $55(7)$ & & $58(7)$ & & $24(6)$ & \\
\hline & 40 & & $0(0)$ & & $15(5)$ & & $4(3)$ & & $0(0)$ \\
\hline
\end{tabular}

Table 2. Example of .txt file used to generate 8 data coordinates.

\begin{tabular}{lccc}
\hline Plate Location & X Coordinate & Y Coordinate & Germ \\
\hline 1 & 424000 & 5208000 & 0 \\
2 & 424002 & 5208000 & 1.5 \\
3 & 424004 & 5208000 & 53 \\
4 & 424006 & 5208000 & 48 \\
5 & 424001 & 5208001 & 0 \\
6 & 424003 & 5208001 & 45 \\
7 & 424005 & 5208001 & 86 \\
8 & 424007 & 5208001 & 0.5 \\
\hline
\end{tabular}

recorded at the XY intersection, and it can be any count from the number of ants to the percent concentration of nitrogen at the $\mathrm{XY}$ intersection. Elevation is a common $\mathrm{z}$ value and is used to create a 3-dimensional image of the spatial relationship between data collected at each XY intersection. However, because it is rarely possible to collect enough $\mathrm{X}, \mathrm{Y}$, and $\mathrm{z}$ values to produce a smooth 3 -dimensional image, researchers use interpolation - the process of using known data points from different spatial locations on the landscape-to create a continuous surface of values (Johnston et al. 2001). The principle underlying spatial interpolation is the First Law of Geography, which states that everything is related to everything else but that near things are more related than distant things or that the zone of influence will decay over distance (Bonham-Carter 1994). It is assumed that as known value locations get farther away from the predicted value location, the spatial autocorrelation will be reduced (Johnston et al. 2001). It is the role of the GIS operator to determine how many known locations, or nearest neighbors, should be used to predict the unknown value. Within the GIS environment, there are various mathematical formulae for interpolation, including kriging, spline, and inverse distance weighting. Each method has its own set of assumptions and capabilities. Kriging would the most suitable

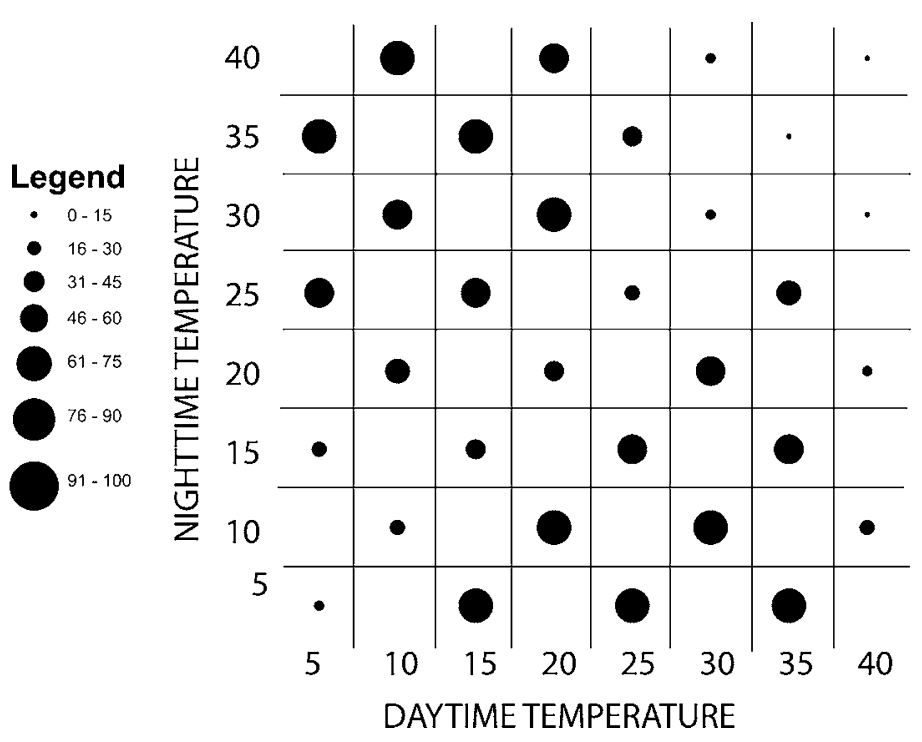

Figure 2. An example of mean germination values represented as graduated symbols for day 6 data. 

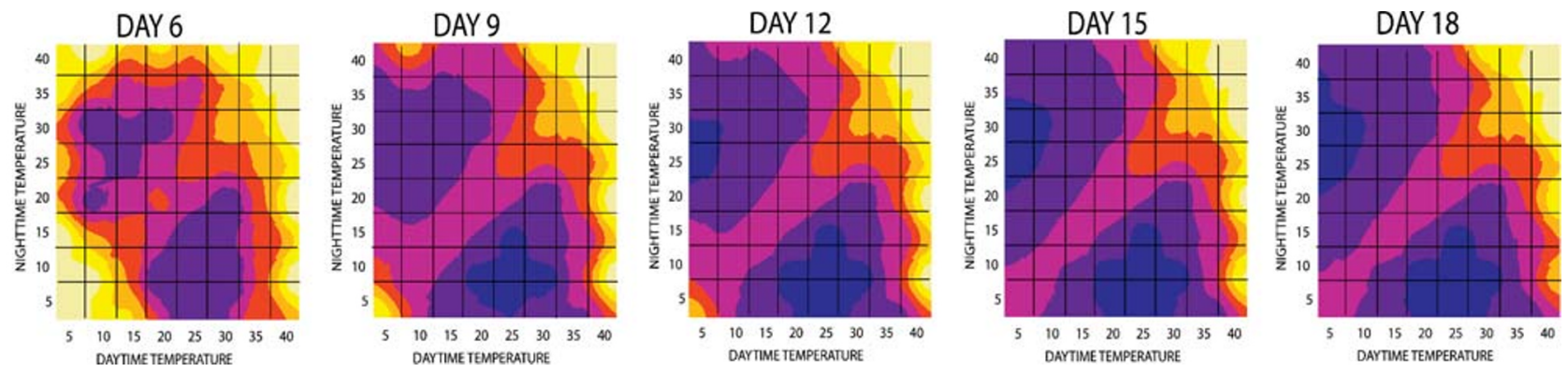

Figure 3. Interpolated images of percent germination over 3-day intervals using ordinary kriging, including a legend and overlaid grid image.

option for calculating germination values because 1) it generates values that do not exceed the highest and lowest values, 2 ) it is good for sample points that are close together and have extreme differences in values, and 3 ) it is well suited for dense, evenly spaced sample point sets (Johnston et al. 2001). The kriging method uses weighted zone of influence decay rates that are optimized at each interpolation point by considering distance, clustering, and spatial autocorrelation (BonhamCarter 1994). Ordinary kriging was used to create all maps produced in this article. The formula for ordinary kriging used within the ESRI ${ }^{\circledR}$ ArcGIS $^{\mathrm{TM}}$ Geostatistical Analyst extension within ArcMap v8.2 $2^{\mathrm{TM}}$ program (ArcMap 2002) is (Johnston et al. 2001)

$$
Z(s)=\mu(s)+\varepsilon(s)
$$

where

$Z(s)$ is the unknown germination value being predicted for the location $s$,

$\mu(s)$ represents an unknown constant, and

$\varepsilon(s)$ is an error term, assumed to be 0 .

Just as known elevation values ( $\mathrm{z}$ value) can be used to interpolate 3-dimensional images across the landscape, the known germination values ( $\mathrm{z}$ value) can be used to interpolate potential germination values across the thermogradient plate.

\section{Image Creation Process}

Following data collection, a text (.txt) file was created with 3 columns: X, Y, representing spatial coordinates, and Germ, expressed as a percent value, as the $\mathrm{z}$ value. The text file was saved in ASCII format (Table 2). The researcher can use any initial plausible XY coordinate to serve as the "southwest" corner of the thermogradient plate. However, all ensuing coordinates must be in relation to the first XY coordinate. Because each digit increment in Universal Transverse Mercador coordinates represents $1 \mathrm{~m}$ on the Earth's surface, it is an easy coordinate system to use to create an evenly spaced grid of data coordinates, thus creating a surface that is analogous to the landscape-level context typically analyzed within a GIS environment. To ensure accuracy, the data coordinates were spaced in a manner that reflected their actual location on the thermogradient plate (data points). For example, the data points in this example were in a checkerboard fashion, and therefore the offset pattern was reflected with similar gaps in the XY spatial coordinates. The text file was imported into ArcMap ${ }^{\mathrm{TM}}$, and the XY data were presented. An example of the data points' pattern and mean germination values are presented in Figure 2 as graduated symbols. However, a more mathematically complete and visually pleasing presentation of the data can be produced using interpolation.

In ArcMap v.8.2 $2^{\mathrm{TM}}$ Geostatistical Analyst, the data points were presented and then interpolated into a raster using ordinary kriging prediction mapping. The spherical semivariogram model was used incorporating 4 nearest neighbors in the search radius. Map properties such as classification classes and color ramp were adjusted. Using the "draw" tool in ArcMap AM $^{\mathrm{TM}}$, an even grid was created across the surface to represent the general temperature increments on the thermogradient plate. Text and a legend were added, and the complete image was exported as a Tag Image File Format (.tiff). These procedures were repeated for each time interval (Fig. 3).

\section{DISCUSSION}

The goal of research is to effectively translate data into a comprehensible format that will be understood and utilized within the scientific community. Yet research is a fast-paced environment where information can be overlooked and disregarded if it is not easily understood. Therefore, it is advantageous for researchers to present data in the most visually impressive and simplistic manner.

For over a decade, GIS has been well utilized within the geosciences community for presenting visually impressive images of geographical data. However, GIS can be utilized as a tool within other disciplines to present data other than that of a geographic nature. For example, in this paper, GIS allowed for a clear and dynamic presentation of data relating to seed germination over time on a 2-way thermogradient plate.

However, GIS users must be aware of and understand the data manipulation that occurs when using an interpolation formula such as kriging. Also, given that the GIS technique discussed in this paper groups germination data into categories (i.e. 16\%$30 \%, 31 \%-45 \%$ ), it may be prudent to combine GIS images with a tabular format to ensure a thorough presentation of germination data. Finally, the reader is encouraged to contemplate how the particular GIS techniques discussed in this paper could be incorporated into their data presentation repertoire.

\section{REFERENCES}

ArcMap [computer program]. 2002. Version 8.2. Redlands, CA: Environmental Systems Research Institute, Inc. 
Bonham-Carter, G. F. 1994. Geographic information systems for geoscientists: Modelling with GIS. New York, NY: Pergamon. 398 p.

Johnston, K., J. M. Ver Hoef, K. KRISVORUChKo, and N. Lucus. 2001. Using ArcGISTM Geostatistical Analyst-GIS by ESRI ${ }^{\mathrm{TM}}$. Redlands, CA: Environmental Systems Research Institute, Inc. 300 p.

LARSEN, A. L. 1971. The thermogradient plate for seed germination research: Construction plans and procedures. Washington, DC: US Government Printing Office. US Department of Agriculture, ARS 51-41.

Larsen, A. L., D. P. Montgillion, and E. M. Schroeder. 1973. Germination of dormant and nondormant rescuegrass seed on the thermogradient plate. Agronomy Journal 65(1):56-59.

Lodge, G. M., AND R. D. B. Whalley. 2002. Fate of annual pasture legumes seeds on a two-way thermogradient plate. The Rangeland Journal 24(2):227-241.

O'ConnoR, M. 1991. Writing successfully in science. London: HarperCollins Academic. $229 \mathrm{p}$.

University of Guelph Teaching Support Services. 2003. Effective poster design. Available at: http://www.soe.uoguelph.ca/webfiles/agalvez/poster/. Accessed 14 January 2004

WebB, D. M., C. W. Smith, and J. Schulz-Schaeffer. 1987. Amaranth seedling emergence as affected by seeding depth and temperature on a thermogradient plate. Agronomy Journal 79(1):23-26.

Young, J. A., C. D. Clements, and T. Jones. 2003. Germination of seeds of big and bottlebrush squirreltail. Journal of Range Management 56(3):277-280. 